\title{
Comparative analysis of endurance of not hearing and hearing students
}

\author{
Dagmara Iwańska, Anna Madej, Czesław Urbanik \\ Department of Biomechanics, Jozef Pilsudski's University of Physical Education, Warsaw
}

\section{Summary}

Study aim: Sport participation is important for deaf children, as participants experience physical, psychological and social benefits [23]. This study is a summary of four year's researches on the endurance level of deaf and well hearing girls and boys. The aim of this study was to compare endurance of not hearing and hearing students.

Material and methods: 300 students aged 12,14 and 16 from six Warsaw's schools participated in the study. Students were divided into 12 groups according to three criterions: hearing impairment level, gender and age. The physical fitness was measured with laboratory methods. There was „inclined plane” measurement set used to estimate the endurance level. From the biomechanical point of view the measure of endurance is change of power versus time and total work.

Results: The study result's proved significant differences only between boy's group. Deaf and hearing girls presented similar level of their endurance parameters. The significant differences in results of deaf and well-hearing students were observed in the groups of 14 years old boys. Deaf male students presented 23\% lower $(p<0.01)$ values of maximal power in comparison to their hearing peers. Yet, they were more capable of sustaining the power developed for a longer time, which is proved by significantly higher $(33 \% ; p<0.001)$ regression coefficient $b$. Since maximal power level was lower, the executed work was also significantly lower comparing to well-hearing students' results.

Conclusion: Research proved that deaf students do not vary from their well-hearing peers with regard to the energetic potential. Differences described in the literature and recorded in our research are probably the result of environmental (social) factors and different models of gaining movement habits.

\section{Key words: Power - Endurance - Not hearing - Hearing children}

\section{Introduction}

Apart from many natural factors such as gravitation, air-pressure, temperature, humidity, light radiation etc., acoustical phenomena also play an important role in human life. Information on a surrounding external world is an integral part of human life. Elimination of any of such elements may constrain human's capacity to function properly. Damaged hearing limits reception of acoustic phenomena and may lead to intellectual and physical fitness disorder.

Consequences of hearing defect were broadly discussed in the literature $[14,26]$. Deaf children experience difficulties in their individual development, which may be reflected in their social, emotional, cognitive, language and motor skills $[1,20]$. Sport participation is important for deaf children, as participants experience physical, psychological and social benefits [26]. Furthermore, a deaf who experiences success in physical activity or sport might be more likely to adopt a physically active lifestyle [18].

In majority of the research, physical fitness has been evaluated on the basis of exercises and motor tests, however results of such carried out by various scientists were often contradictory. Some claimed that physical fitness of children with hearing disability is usually lower than well hearing children $[6,24,31]$. Winnik and Short [29] did not notice any differences between the deaf and hard-of-hearing children, however the hearing children scored higher in strength and stamina of the abdominal muscles. Others indicated that physical fitness of children with hearing disability does not significantly differ from the results of their healthy peers $[7,26]$. The reason of such contrary opinions is most likely the fact that the movement result being evaluated on the fitness tests depends on many factors $[10$, 13]. In more recent studies, inferior motor performance was found in deaf children, possibly attributable to a longer reaction time [23]. Some research studies 
included profoundly deaf children using cochlear implants $[4,13,25]$. Results of these studies are contradictory. Some of the studies found no differences in motor skill between deaf children with a CI and hearing children and two studies found inferior motor skill performance in deaf children with CI. These include several factors also: biomechanical, physiological, psychological features, technique and movement tactics. They constitute human movement potential, which may express itself in a certain circumstances. On the other hand, evaluation of energetic potential while all external factors and conditions are eliminated, show the actual state of subjects motor potential. Moreover, important aspect which appears also in many studies while examining physical fitness is the need to differentiate deaf children in the aspect of existing in many cases vestibule disorder [3].

Although one may find research reports concerning physical fitness measured under laboratory conditions $[12,16,30]$. Laboratory measurements are mostly used in body balance estimation [5, 26]. Therefore, attempting to carry on a research on deaf subjects we have applied laboratory methods which make such evaluation possible and which comply with the above-mentioned conditions.

Endurance is considered to be a primary physical feature and is defined as the capacity of executing physical effort without significant fatigue [8]. From the definition it appears that endurance manifests itself in a long lasting effort on given intensity, carried on till the first signs of fatigue. Secondly, it may manifest itself also in decrease of the capacity to carry on with the exercise while fatigue increases [8]. Therefore, the generally accepted measure of endurance is oxygen up take.

From the biomechanical point of view the measure of endurance is change of power versus time, which enables to evaluate the endurance both for short and long lasting efforts [9]. The aim of this study was to compare endurance of not hearing and hearing students. Moreover review of literature and research conducted in subjects with hearing impairment, allow to take hypothesis indicating bigger differences between hearing and not hearing students in tests in which technique of exercise influence the result whereas the level of biomechanical features is not determined by hearing impairment.

\section{Material and methods}

\section{Material}

300 students aged 12, 14 and 16 from six Warsaw's schools participated in the study. Students were divided into 12 groups according to three criterions: hearing and not hearing; girls and boys; 12, 14, 16-years old. Descriptive data of subjects are presented in Table 1.

The reasons for losing the hearing varied. For $18 \%$ of deaf students it was an inherited disability, for 23\% it was a congenital loss, while $14 \%$ of children lost hearing in a result of past diseases in an early infancy. For $2 \%$ of students hearing damage was puerperal and $8,3 \%$ because of mother disease in pregnancy. For $42 \%$ of the group of deaf, reasons of the loss of hearing were unknown. The scope of hearing loss in all deaf groups, according to Van Uden classification, indicates serious hearing impairment. All subjects were common comprehensive schools students and were not members of sport profile classes. All of them were characterized with similar level of body mass and height in all age categories. Students with hearing impairment are not delayed in physical development. It was observed in all age groups.

\section{Methods}

There was „inclined plane" measurement set used to estimate the endurance level. Subjects laying back on sliding trolley were executing 40 max "take-offs" from the platform (see Figure 1).

Tab. 1. Selected anthropological features of students and hearing loss

\begin{tabular}{|c|c|c|c|c|c|c|c|c|}
\hline \multirow[b]{2}{*}{ group } & \multicolumn{4}{|c|}{ Girls } & \multicolumn{4}{|c|}{ Boys } \\
\hline & $\mathrm{N}$ & $\begin{array}{c}\text { hearing loss } \\
{[\mathrm{dB}]}\end{array}$ & $\begin{array}{c}\text { mass } \\
{[\mathrm{kg}]}\end{array}$ & $\begin{array}{l}\text { height } \\
{[\mathrm{cm}]}\end{array}$ & $\mathrm{n}$ & $\begin{array}{c}\text { hearing loss } \\
{[\mathrm{dB}]}\end{array}$ & $\begin{array}{c}\text { mass } \\
{[\mathrm{kg}]}\end{array}$ & $\begin{array}{l}\text { height } \\
{[\mathrm{cm}]}\end{array}$ \\
\hline Inhr & 25 & $89.3 \pm 15.0$ & $44.4 \pm 7.8$ & $154.8 \pm 5.7$ & 25 & $93,6 \pm 12,4$ & $47,2 \pm 8,9$ & $159,1 \pm 9,5$ \\
\hline IInhr & 21 & $93.9 \pm 9.0$ & $55,2 \pm 4,8$ & $162,2 \pm 5,4$ & 18 & $85,7 \pm 16,3$ & $56,3 \pm 10,6$ & $168,3 \pm 9,7$ \\
\hline IIInhr & 14 & $81.0 \pm 21.8$ & $54,4 \pm 4,8$ & $163,4 \pm 6,2$ & 15 & $97,3 \pm 11,3$ & $62,2 \pm 8,0$ & $175,6 \pm 7,8$ \\
\hline Ihr & 44 & & $47,4 \pm 7,5$ & $158,1 \pm 8,2$ & 47 & & $44,7 \pm 9,7$ & $157,1 \pm 8,2$ \\
\hline IIhr & 29 & & $54,3 \pm 7,0$ & $164,8 \pm 6,0$ & 19 & & $62,5 \pm 9,1$ & $172,3 \pm 8,6$ \\
\hline IIIhr & 24 & & $58,0 \pm 9,5$ & $166,2 \pm 7,0$ & 19 & & $67,9 \pm 10,8$ & $178,7 \pm 5,6$ \\
\hline
\end{tabular}

I, II, III- age group, adequately 12 years, 14 years, 16 years, nhr- not hearing, hr-hearing. 


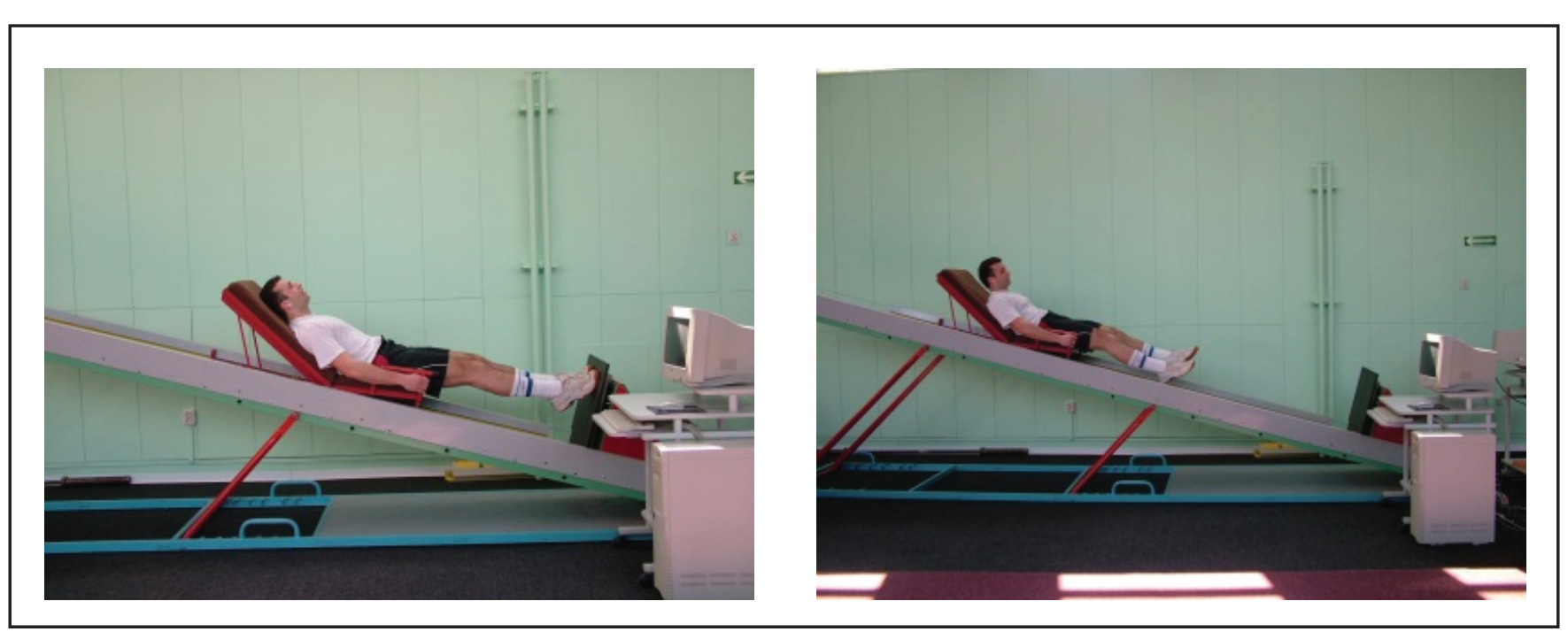

Fig. 1. The system „inclined plane” to measure the rate of power versus time decline.

Subject taking off from the platform was giving the whole system (trolley and the body) certain velocity, and after the velocity was lost, it was going downward, breaking down the velocity and taking off again. There was an electromagnetic detector installed, which measured the time, and impulse rotation converter added to measure the distance. On the basis of measured movement parameters there was a kinetic energy of take offs and landing down during the exercise calculated.

$$
E_{k}=L_{u}=\frac{1}{2}\left(m_{1}+m_{2}\right) \cdot v_{\max }^{2}
$$

where: $E_{k}-$ kinetic energy, $L_{u}-$ work, $m_{1}-$ trolley mass, $m_{2}$ - mass of a subject, $v_{\max }-$ take off velocity.

There was a medium power of take off calculated next:

$$
P=\frac{L_{u}}{t_{k}}
$$

where: $P$ - power output, $t_{k}$ - time of take off.

All power values from a whole set of take offs were considered. Assuming that power versus time change is an indicator of the endurance, the results were approximated with an equation of a regression:

$$
P=a-b
$$

It was assumed, that endurance indicator is the rate of power versus time decline, described by a " $b$ " regression coefficient. The more it is closer to " 0 ", the higher is the endurance level. After receiving measurements, there were mean values calculated for the groups. results were averaged for a whole group.

Normal distribution was tested by Shapiro-Wilk test. Differences of power level were tested by multifactor analysis of variance (ANOVA) and covariance
(ANCOVA). Pearson correlation coefficient was used to analyse variables interactions. The level of $p<0.05$ was considered significant.

\section{Results}

Relative and absolute values of maximal power and regression coefficient value averaged for groups were subjected to statistical analysis. In some cases variables were not normally distributed. Therefore, results were subjected to a logarithm transformation. After this mathematical procedure, distribution of variables was close to the expected distribution.

All students executed 40 maximum take-offs on „incline plane" to full lower extremities flexion during breaking phase before next take off. Maximum power $\left(P_{\max }\right)$ and work $(\mathrm{W})$ were recorded for each take-off. Figure 2 shows the example of a power change in time for a whole set of 40 take-offs.

The youngest deaf students represented endurance level similar to their peers, both in case of boys and girls (Figure 2, Table 2). Significant gender differences were

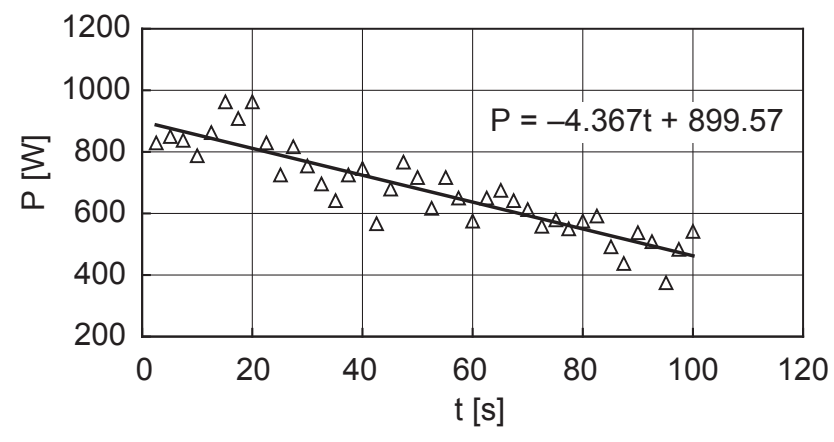

Fig. 2. Example of a power change in time approximated with a regression equation. 
Tab. 2. Mean values $\pm \mathrm{SD}$ of executed work $\Sigma \mathrm{W}[\mathrm{kJ}]$ for groups of 12 years old not hearing and hearing students

\begin{tabular}{lccc}
\hline & \multicolumn{3}{c}{$\Sigma \mathrm{W}[\mathrm{kJ}]$} \\
group & $\mathrm{nhr}$ & $p$ & $\mathrm{hr}$ \\
\hline girls & $7.0 \pm 1.6$ & $0.01^{\#}$ & $8.5 \pm 2.9$ \\
boys & $10.3 \pm 4.1$ & & $9.4 \pm 3.4$ \\
\hline
\end{tabular}

$P$ - significance level; $p<0.05-* ; p<0.01-* * ; p<0.001-* * * \#$ - different between not hearing girls and boys.

noticed in case of 12 years old children. $\left(\mathrm{F}_{(1.116)}=8.71\right.$; $p<0.01$ ). Yet, on the basis of a detailed analysis significant differences were noticed only within deaf students' groups. Statistically significant differences were recorded for the maximal power level $(33 \% ; p<0.001)$ and executed work $(32 \% ; p<0.01)$. In both cases girls obtained lower scores.

For all groups there was relationship found out between the maximal power and total executed work and body mass of students $(p<0.01)$. ANCOVA considering body mass as an associated (disturbing) variable also revealed gender as a variable differentiating level of recorded parameters (for $P_{\max }: \mathrm{F}_{1.115}=14.3 ; p<0.001$ and for $\Sigma \mathrm{W}: \mathrm{F}_{1.115}=18.2 ; p<0.01$ respectively).

The significant differences in results of deaf and well-hearing students were observed in the groups of 14 years old boys. Deaf male students presented 23\% lower $(p<0.01)$ values of maximal power (Figure 3A)
Tab. 3. Mean values \pm SD of executed work $\Sigma \mathrm{W}[\mathrm{kJ}]$ for groups of 14 years old not hearing and hearing students

\begin{tabular}{lcccc}
\hline & \multicolumn{4}{c}{$\sum \mathrm{W}[\mathrm{kJ}]$} \\
group & $\mathrm{nhr}$ & $p$ & $\mathrm{hr}$ & $p$ \\
\hline girls & $9.8 \pm 2.7$ & $0.05^{\#}$ & $10.6 \pm 2.1$ & $0.001^{\# \#}$ \\
boys & $12.6 \pm 3.6$ & & $16.0 \pm 3.1$ & \\
$p$ & & $0.001^{\# \# \#}$ & & \\
\hline
\end{tabular}

$p<0.05-* ; p<0.01-* * ; p<0.001-* * * *$ - different between

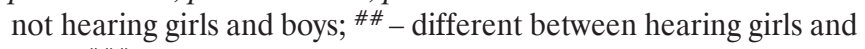
boys; \#\# - different between hearing and not hearing boys.

in comparison to their hearing peers. Yet, they were more capable of sustaining the power developed for a longer time, which is proved by significantly higher $(33 \%$; $p<0.001) b$ coefficient (Figure 3B). Since maximal power level was lower, the executed work was also significantly lower comparing to well-hearing students' results (Table 3 ).

Endurance is a feature characterized by a similar development for both girls and boys in case of early school age. Following the $12^{\text {th }}$ year of age one observes increasing gender differences. The highest endurance level is observed at the age of 13-15 in case of girls and after the $15^{\text {th }}$ year of age in case of boys. Comparison of boys and girls revealed much higher dynamic potential of boys, both in case of deaf and well-hearing groups. The difference between maximal power $P_{\max }$ obtained
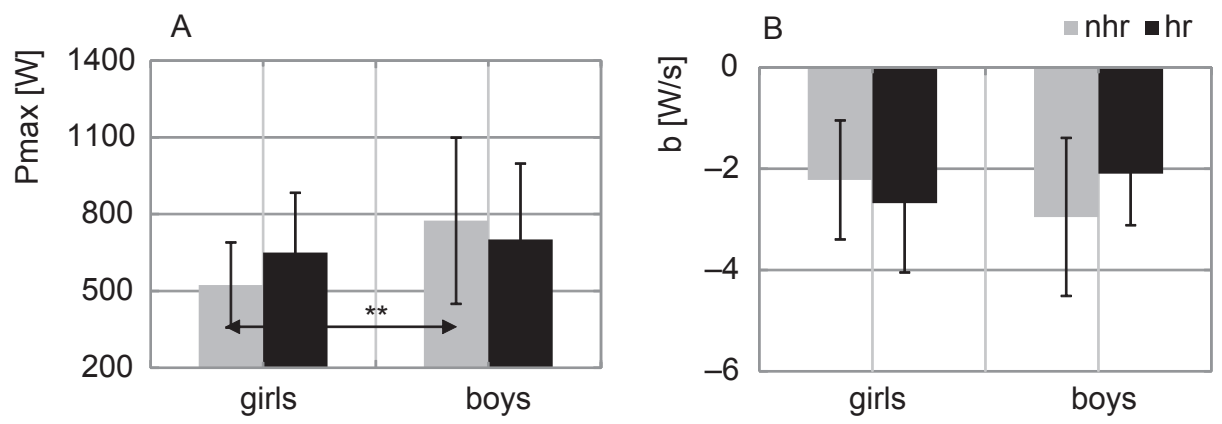

Fig. 3 Mean values \pm SD of maximal power $P_{\max }[\mathrm{W}](\mathrm{A})$ and regression coefficient b [W/s] (B) obtained by 12 years old not hearing (nhr) and hearing (hr); $p-$ significance level; $p<0.05-* ; p<0.01-* * ; p<0.001-* * *$
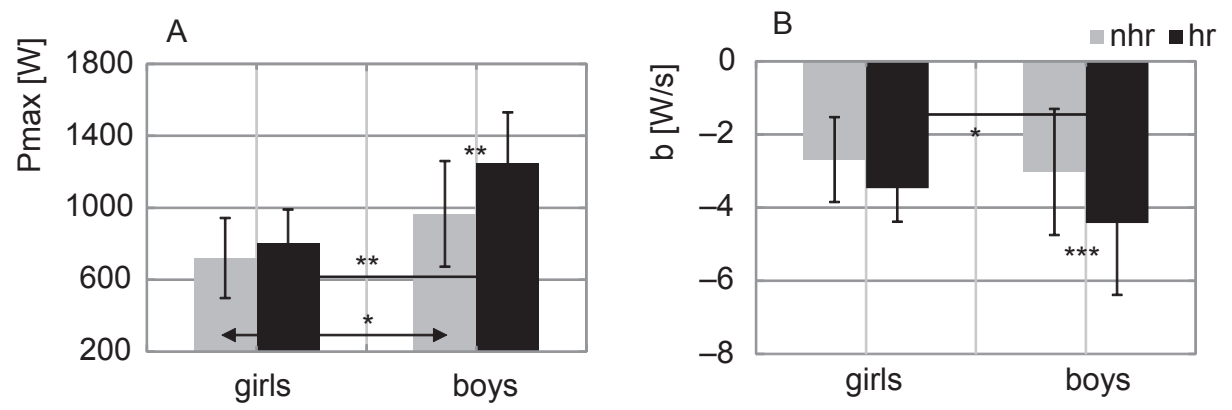

Fig. 4. Mean values $\pm \mathrm{SD}$ of maximal power $P_{\max }[\mathrm{W}](\mathrm{A})$ and regression coefficient $\mathrm{b}[\mathrm{W} / \mathrm{s}]$ (B) obtained by 14 years old not hearing and hearing students; $p<0.05-{ }^{*} ; p<0.01-{ }^{* *} ; p<0.001-* * *$ 

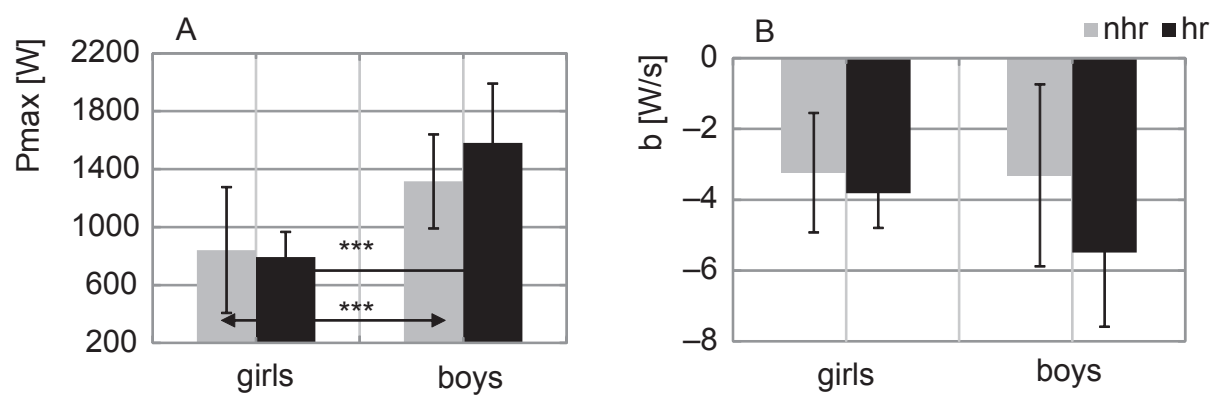

Fig.5. Mean values $\pm \mathrm{SD}$ of maximal power $\mathrm{P}_{\max }[\mathrm{W}](\mathrm{A})$ and regression coefficient $\mathrm{b}[\mathrm{W} / \mathrm{s}]$ (B) obtained by 16 years old not hearing (nhr) and hearing (hr) students; $p<0,05-{ }^{*} ; p<0,01-* * ; p<0,001-* * *$

by girls and boys with hearing impairment was even up to $25 \%(p<0.05)$. Higher difference was observed in case of the control group. Well-hearing male students obtained 36\% ( $<<0.001)$ higher maximal power value $P_{\max }$ than their female peers. Regression coefficient (b) was almost the same in all groups, while boys, in comparison to girls, executed significantly higher total work, which may indicate higher endurance level of boys.

Gender related differences ware also noticed in older age groups, both in case of deaf and wellhearing groups, girls reached lower values of power $\left(\mathrm{F}_{1.64}=107.4, p<0.001\right)$. In comparison to their female peers boys reached higher maximal power: by $36 \%(p<0.001)$ in a hearing impairment group, and by $50 \%(p<0.001)$ in a well-hearing group.

Boys exceeded girls also in case of a total executed work (Table 4). Boys from deaf group executed 32\% more work than their female group mates $(p<0.001)$. Comparison of results within the well-hearing group revealed the boys - girls difference of as much as $44 \%$ $(p<0.001)$.

Based on detailed analysis of calculated variables, it was also determined that students with hearing impairment executed $18 \%(p<0.05)$ less work than their male hearing peers.

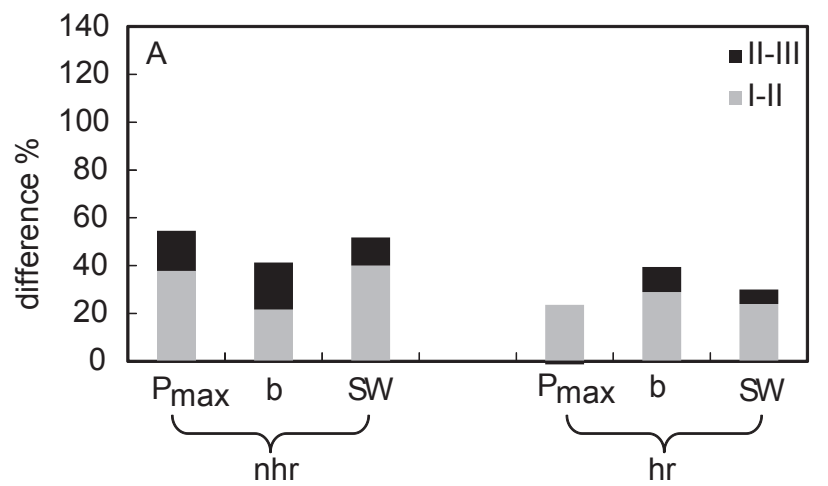

Tab. 4. Mean values \pm SD of executed work $\Sigma W[\mathrm{~kJ}]$ in not hearing (nhr) and hearing (hr) groups of 16 years old students

\begin{tabular}{lcccc}
\hline & \multicolumn{4}{c}{$\Sigma \mathrm{W}[\mathrm{kJ}]$} \\
group & $\mathrm{nhr}$ & $p$ & $\mathrm{Hr}$ & $p$ \\
\hline girls & $11.0 \pm 5.3$ & $0.001^{\#}$ & $11.2 \pm 2.0$ & \\
boys & $16.4 \pm 2.9$ & & $19.8 \pm 3.8$ & $0.001^{\# \#}$ \\
$p$ & & $0.05^{\# \# \#}$ & & \\
\hline
\end{tabular}

$p$ - significance level; $p<0,05-* ; p<0,01-* * ; \mathrm{p}<0.001-* * *$ \# - different between not hearing girls and boys; ${ }^{\# \#}$ - different between hearing girls and boys; \#\#\# - different between hearing and not hearing boys.

What is interesting, hearing impaired students presented postponed development of measured parameters in comparison to control groups. It is particularly evident in male groups (Fig. 6B).

It was notices that higher per cent differences within the group of hearing impaired group occurred between the 2nd (II) and 3rd (III) age group, and lower in case of 1st (I) and 2nd (II) group - in contrary to wellhearing group. Moreover, total difference between the youngest and the oldest group was much lower among deaf groups and did not exceed $70 \%$ of maximal

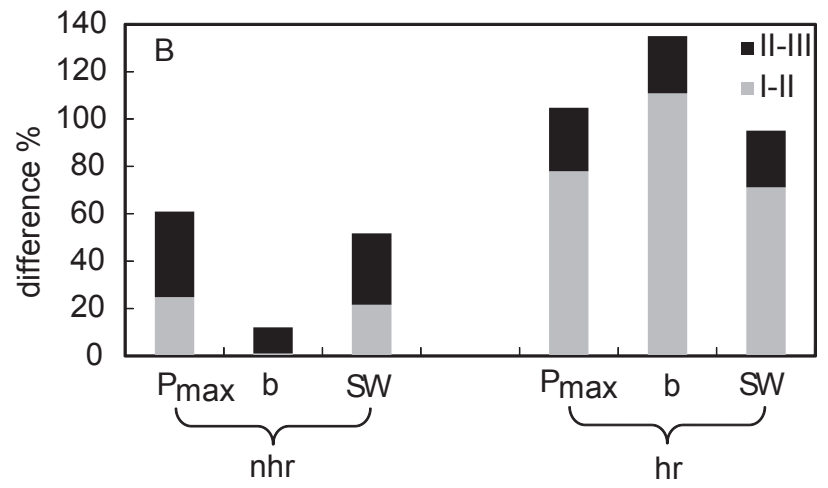

Fig. 6. Percent differences between specific age categories for females (A) and males (B) for measured variables. I-II the difference between 1st (I) and 2nd (II) age group; II-III the difference between 2nd (II) and 3rd (II) age group 
power value. Much higher differences were observed for control groups. They exceeded $100 \%$ for the same parameter. It also concerns total work students were able to execute during the whole set of 40 take-offs. For deaf students the most persistent parameter was $b$ coefficient. The difference between 1st (I) and 3rd (II) age group reached $12 \%$. Regression coefficient varied within the group of well-hearing students. It reached the level of $110 \%$ of difference between the youngest and the oldest group, which was related to higher dynamic parameters differences within male groups. Such discrepancy was not observed between female groups.

\section{Discussion}

The endurance is very important for deaf people. The reason for this is the fact that majority of deaf youth starts working physically after graduating their schools. Physical fitness and ability of undertaking long-term physical efforts are often the decisive factors in their life.

On the basis of reviewed literature and own research there was the following hypothesis constructed that deaf persons' energetic potential do not vary from energetic potential of their well-hearing peers in case when external factors influence is limited. Differences noticed between these groups, mentioned in the literature, originate from environmental factors and different process of learning movement habits.

People with hearing impairment are not delayed in physical development, and therefore we presume the physical fitness difference are related to social determinants, school type and physical education curricula and living conditions [2]. The fact is that hearing impaired students from early education learn in boarding schools, and this may have significant impact on their development. Moreover, it should be claimed that human physical fitness is a feature which is much more determined by not-genetic factors than it is the case with e.g. somatic development [22].

The analysis of study results enables to evaluate positively the endurance level represented by deaf students. In contrary to the results obtained by Zwierzchowska et al [31] evaluating motor fitness of deaf children observed that energetic abilities, mainly strength and endurance remain at a low level. The authors suggest that the differences in the level of energetic and coordination abilities, with the predominance of the second ones in deaf children may be explained by the lack of hearing ability and appropriate compensations that follow.

Research on endurance of deaf students on the background of laboratory methods conduced Hattina et al [12]. Authors compared endurance of deaf and blind students.

They conducted tests on a ergocycle and stated that the endurance not hearing students was $9,5 \%$ worse and maximum oxygen uptake was $17,5 \%$ worse than that of blind students.

Other researchers have determined the aerobic capacity of handball players with hearing impairment as compared with the healthy ones. Players with hearing impairment attained significantly lower values of oxygen pulse and maximum speed (by 12\%), also lung ventilation (by 11\%) and tidal volume (by 14\%) compared with healthy group. The authors also showed insignificant differences between relative $\mathrm{VO}_{2}$ max. Therefore, the lower results attained by handball players with hearing impairment compared with the healthy ones could be attributed to twice lower training volume per week.

The aim of another study was to determine influence of physical effort (performed on incline plane) on respiratory apparatus efficiency in deaf students [15]. In the study relationships between MMV (maximal voluntary ventilation) and power values $\left(P_{\text {mean }}\right.$, $\left.P_{\max }\right)$ during dynamic exercise were examined. Authors drew attention to increase of significance level of correlation coefficient while increase of work, which means after 20, then 40 take offs on incline plane. However comparing mean values of vital capacity (VC) with due values significant difference was revealed to deaf disadvantage. Lungs capacity prove volume capability of lungs and examination is performed under rest conditions while MVV is dynamic and shows mechanical abilities of lungs. Authors suggest that the reason of lower performance of deaf students may be caused by lack of their ability to perform breath-out phase caused by limited speech. It can be assumed that lower lungs capacity is the result of lack of training which can give speech and may have no influence of respiratory apparatus function during exercise in deaf subjects [15]. Therefore it seems that method used in present study is appropriate do diagnose endurance abilities because it reduce influence of both technique and environment factors as well as it is based on energy changes occurring during maximal effort $[9,28]$. Calculated mechanical power can't be however interpreted in explicit as expended chemical energy which was also stated by Oksanen et al. [19] i Kyrolainen and Komi [17].

In other laboratory studies it was also proved that deaf subjects didn't differ significantly from their peers. Significant differences were revealed only in tests where the result might have been influenced by coordination and postural balance $[5,11,16,27]$.

Moreover analyzing the pace of changes occurring in respective age groups of 12-14, 14-16, deaf boys 
apart, it was shown the highest rate (\% differences) between I and II age group. IN the group of deaf boys the highest rate was between the groups of 14 and 16 years old. The reason for this may be suspected in environment factors not in the fact of hearing loss.

Similar delay in acquiring primary physical fitness components by the deaf were observed by Butterfied [2] and Dammer [7]. These authors see the reason of such delay also in environmental and social factors and in the distorted communication process (quantity and quality of instruction while shaping physical skills) requiring the ability of using sign language. Similar suggestions were done by Hartman et al. [14].

Also similar relationships were observed for wellhearing boys by Przewęda [22]. According to this author the impact of genetic determinants of physical fitness is high till the age of puberty. Afterwards, environmental and social factors become more important. This pattern is more visible in case of males. Females' physical fitness is more influenced by genetics and more resistant to environmental and social influences.

\section{Conclusions}

Our research proved that deaf students do not vary from their well-hearing peers with regard to the energetic potential. Differences described in the literature and recorded in our research are probably the result of environmental (social) factors and different models of gaining movement habits. Yet, it should be underlined that there is a need of observation and permanent supervision over the physical fitness of hearing impaired children. It is of great importance especially in case of children in boarding schools, who are more prone to external factors influence.

The study also indicate the need to modify programs of physical education to improve specific motor abilities. For this purpose it is necessary to take into consideration other factors influencing the performance such as the cause of deafness, type of hearing loss, requirements for each test (simple or complex; technique execution or performance precision), previous motor experiences, community as well as methods of communication [11].

\section{References}

1. Bat-Chava Y., Martin D., Kosciw J.G. (2005) Longitudinal improvements in communication and socialization of deaf children with cochlear implants and hearing aids: Evidence from parental reports. J. Child Psychol. Psych. and Allied Disciplines, 46: 1287-1296.
2. Butterfield S.A. (1991) Influence of age, sex, hearing loss and balance on development of running by deaf children. Percept. Mot. Skills, 73: 624-626.

3. Crowe T.K., Horak F.B. (1988) Motor proficiency associated with vestibular deficits in children with hearing impairments. Phys. Ther, 68: 10.

4. Cushing S.L., Chia R., James A.L., Papsin B.C., Gordon K.A. (2008) A test of static and dynamic balance function in children with cochlear implants. Arch.Otolaryngol. Head Neck Surg., 134(1): 34-38.

5. De Kegel A., Dhooge I., Peersman W., Rijckaert J., Baetens T., Cambier D., Van Waelvelde H. (2010) Constructor validity of the assessment of balance in children who are developing typically and children whit hearing inmpairments. Phys. Ther, 90(12): 1783-1794.

6. Dzimira-Pyzio J., Demczuk-Włodarczyk E., Bieć E. (2007) Evaluation of postural balance in standing position in deaf children aged 11-13 years. Fizjoterapia, 15(1): 40-43. ISSN 1230-8323.

7. Dummer G.M., Haubenstriker J.L., Stewart D.A. (1996) Motor Skill Performances of Children Who Are Deaf. Adapt. Phys. Activ. Quarterly, 13: 400-414.

8. Enoka R.M. (2008) Neuromechanics of human movement, University of Colorado at Boulder. Human Kinetics. 317-234.

9. Fidelus K., Urbanik Cz., Grudniak K. (1994) Time Changes of Power Output as an Endurance Index of Lower Limb Muscle. Biology of Sport, 11: 115-121.

10. Gheysen F., Loots G., Van Waelvelde H. (2008) Motor development of deaf children with and without cochlear implants. J. Deaf Stud. Deaf Educ., 13(2): 215-224.

11. Gkouvatizi A.N., Mantis K., Pilianidis T. (2010) The impact of hearing loss degree and age on upper limb coordination ability in hearing, deaf and hard of hearing pupils. Studies in Physical Culture and Tourism, 17(2): 147-155.

12. Hattin H., Fraser M., Ward G.R., Shephaed R. (1986) Are deaf children unusually fit. A comparison of fitness between deaf and blind children. Adapt. Phys. Activ. Quarterly, 3: 268-275.

13. Horn D.L., Pisoni D.B., Sanders M., Miyamoto R.T. (2005) Behavioral assessment of prelingually deaf children before cochlear implantation. The Laryngoscope, 15: 1603-1611.

14. Hartman E., Houwen S., Visscher Ch. (2011) Motor performance and sport participation in deaf elementary school children. Adapt. Phys. Activ. Quarterly, 28: 132-145.

15. Iwańska D., Urbanik Cz., Mastalerz A., Madej A. (1999) The function respiration research in the time of effort at the people with hearing disorders. Acta Bioeng. Biomech., 1(1): 193-196.

16. Iwańska D., Urbanik Cz. (2003) Analysis of dynamic capabilites of children with hearing impairment. Acta Bioeng. Biomech., 5(1): 189-195. 
17. Kyröläinen H., Komi P.V. (1995) Differences in mechanical efficiency between power- and endurancetrained athletes while jumping. Eur J. Appl. Physiol., 70: 36-44.

18. Liberman L.J., Volding L., Winnick J.P. (2004) Comparing motor development of deaf children of deaf parents with deaf children of hearing parents. American Annals of the Deaf, 149(3): 281-289.

19. Oksanen P., Kyröläinen H., Komi P.V. (1990) Estimation of errors in the mechanical efficiency. Eur. J. Appl. Physiol., 61: 473-478.

20. Obrzut J.E., Maddock G.J., Lee C.P. (1999) Determinants of self-concept in deaf and hard of hearing children. J. Dev. Phys. Disabil., 11: 237-251.

21. Potter CN., Silverman LN. (1984) Characteristic of vestibular function and static balance skill in deaf children. Phys. Ther., 64(7).

22. Przewęda R. (1985) Uwarunkowania poziomu sprawności fizycznej polskiej młodzieży szkolnej. Z Warsztatów Badawczych, Warszawa.

23. Savelsbergh G.J.P., Netelenbos J.B., Whiting H.T.A. (1991) Auditory perception and the control of spatially coordinated action of deaf and hearing children. J. Child Psychol. Psych. and Allied Disciplines, 32(3): 489-500.

24. Schlumberger E., Narbona J., Manrique M. (2004) non-verbal development children with deafness with and without cochlear implants. Dev. Med. Child Neurol., 46: 599-606.

25. Shin M.S., Kim S.K., Kim S.S., Park M.H., Kim C.S., Oh S.H. (2007) Comparison of cognitive function in deaf children between before and after cochlear implant. Ear and Hearing, 28(2): 22-28.

26. Stewart D.A., Robinson J., McCarthy D. (1991) Participation in Deaf Sport: Characteristics of Deaf Athletes. Adapt. Phys. Activ. Quarterly, 8: 136-145.

27. Suarez H., Angeli S., Suarez A., Rosales B., Carrera X., Alonso R. (2007) Balance sensory organization in children with profound hearing loss and cochlear implants. Int. J. Pediatr. Otorhinolaryngol., 71.

28. Urbanik Cz., Ubukata O. (1985) The influence of training tith concentric and eccentric work on the force and velocity characteristics of muscle. IX International Series on Biomechanics. Human Kinetics Publishers, Inc., Champaign, Ilinois USA. 5: 77-81.

29. Winnick J., Short F. (1986) Physical fitness of adolescents with auditory impairments. Adapt. Phys. Activ. Quarterly, 3: 58-66.

30. Vujkov S., Dukic M., Drid P. (2010) Aerobic capacity of handball players with hearing impairment. Biomed. Hum. Kinetics, 2: 58-61.

31. Zwierzchowska A., Gawlik K., Grabara M. (2004) Energetic and coordination abilities of deaf children. J. Hum. Kinetics, 11: 83-16.

\section{Received 29.10.2012 \\ Accepted 15.10.2013}

(C) University of Physical Education, Warsaw, Poland 